\title{
Effects of diet and gizzard muscularity on grit use in domestic chickens (\#46973)
}

Second revision

\section{Guidance from your Editor}

Please submit by $\mathbf{1 1}$ Oct $\mathbf{2 0 2 0}$ for the benefit of the authors .

\section{Structure and Criteria}

Please read the 'Structure and Criteria' page for general guidance.

\section{Custom checks}

Make sure you include the custom checks shown below, in your review.

\section{Author notes}

Have you read the author notes on the guidance page?

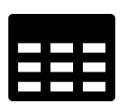

\section{Raw data check}

Review the raw data.

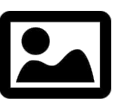

\section{Image check}

Check that figures and images have not been inappropriately manipulated.

Privacy reminder: If uploading an annotated PDF, remove identifiable information to remain anonymous.

\section{Files}

Download and review all files from the materials page.
1 Tracked changes manuscript(s)

1 Rebuttal letter(s)

7 Figure file(s)

16 Table file(s)

6 Raw data file(s)

\section{(9) Custom checks}

\section{Vertebrate animal usage checks}

Have you checked the authors ethical approval statement?

Were the experiments necessary and ethical?

Have you checked our animal research policies? 


\section{Structure your review}

The review form is divided into 5 sections. Please consider these when composing your review:

\section{BASIC REPORTING}

2. EXPERIMENTAL DESIGN

3. VALIDITY OF THE FINDINGS

4. General comments

5. Confidential notes to the editor

You can also annotate this PDF and upload it as part of your review

When ready submit online.

\section{Editorial Criteria}

Use these criteria points to structure your review. The full detailed editorial criteria is on your guidance page.

\section{BASIC REPORTING}

Clear, unambiguous, professional English language used throughout.

Intro \& background to show context. Literature well referenced $\&$ relevant.

Structure conforms to Peer] standards, discipline norm, or improved for clarity.

Figures are relevant, high quality, well labelled \& described.

Raw data supplied (see Peer] policy).

\section{EXPERIMENTAL DESIGN}

Original primary research within Scope of the journal.

Research question well defined, relevant \& meaningful. It is stated how the research fills an identified knowledge gap.

Rigorous investigation performed to a high technical \& ethical standard.

Methods described with sufficient detail \& information to replicate.

\section{VALIDITY OF THE FINDINGS}

Impact and novelty not assessed.

Negative/inconclusive results accepted. Meaningful replication encouraged where rationale $\&$ benefit to literature is clearly stated.

All underlying data have been provided; they are robust, statistically sound, $\&$ controlled.
Speculation is welcome, but should be identified as such.

Conclusions are well stated, linked to original research question $\&$ limited to supporting results. 


\section{Standout \\ reviewing tips}

The best reviewers use these techniques

Tip

\section{Support criticisms with evidence from the text or from other sources}

\section{Give specific suggestions on how to improve the manuscript}

\section{Comment on language and grammar issues}

\author{
Please provide constructive \\ criticism, and avoid personal \\ opinions
}

\section{Example}

Smith et al (J of Methodology, 2005, V3, pp 123) have shown that the analysis you use in Lines 241-250 is not the most appropriate for this situation. Please explain why you used this method.

Your introduction needs more detail. I suggest that you improve the description at lines 57- 86 to provide more justification for your study (specifically, you should expand upon the knowledge gap being filled).

The English language should be improved to ensure that an international audience can clearly understand your text. Some examples where the language could be improved include lines 23, 77, 121, 128 - the current phrasing makes comprehension difficult.

1. Your most important issue

2. The next most important item

3....

4. The least important points

I thank you for providing the raw data, however your supplemental files need more descriptive metadata identifiers to be useful to future readers. Although your results are compelling, the data analysis should be improved in the following ways: $A A, B B, C C$

I commend the authors for their extensive data set, compiled over many years of detailed fieldwork. In addition, the manuscript is clearly written in professional, unambiguous language. If there is a weakness, it is in the statistical analysis (as I have noted above) which should be improved upon before Acceptance.
Comment on strengths (as well as weaknesses) of the manuscript 


\title{
Effects of diet and gizzard muscularity on grit use in domestic chickens
}

\author{
Ryuji Takasaki ${ }^{\text {Corresp., } 1,2}$, Yoshitsugu Kobayashi ${ }^{3}$ \\ 1 Department of Natural History Sciences, Hokkaido University, Sapporo, Japan \\ ${ }^{2}$ Faculty of Biosphere-Geosphere Science, Okayama University of Science, Okayama, Japan \\ 3 Hokkaido University Museum, Hokkaido University, Sapporo, Japan \\ Corresponding Author: Ryuji Takasaki \\ Email address: rtakasaki@big.ous.ac.jp
}

The gizzard is the only gastrointestinal organ for mechanical processing in birds. Many birds use grit in the gizzard to enhance mechanical processing efficiency. We conducted an experiment to test the factors that affect chicken grit use in 68 male layer chicks of Gallus gallus domesticus, which were divided into two different groups in gizzard muscularity (high and low). Within each muscularity group, two different diets were provided (herbivory and non-herbivory) to test whether diet and gizzard muscularity affect grit characteristics including amount, size, and shape (circularity, roundness, and solidity) at different stages of digestion (ingested grit, grit in gizzard, and excreted grit). All animals ingested more grit than they excreted, possibly because excreted grit was below the detection size limit of $0.5 \mathrm{~mm}$ of the present study. The amounts of grit ingested and remained in the gizzard were larger in herbivorous groups, but these groups excreted less grit. Larger, rougher grit was selectively ingested by all chicks, but size preferences were especially pronounced in the herbivorous groups. Grit in the gizzard tended to be larger in herbivorous groups, but the grit in excreta was smaller, whereas the size of excreted grit was larger in groups with less muscular gizzards. Grit in the gizzard was much smoother than the offered and ingested grit, especially in the herbivorous, muscular gizzard groups. Excreted grit in all groups was smoother than the offered grit. These results show that diet affects the characteristics of ingested grit, grit in the gizzard, and excreted grit, whereas gizzard muscularity affects the characteristics of grit in the gizzard and excreted grit. The use of larger sizes and amounts of grit by herbivorous groups may be a response to the needs of digesting hard, coarse materials. The recovered behavioral flexibility of grit use might reflect the omnivorous nature of Gallus gallus domesticus and may aid smooth dietary shifts. The results also show that the shape of grit remaining in the gizzard does not reflect the initial shape of ingested grit, in contrast to previously published ideas. Instead, the shape of grit in the gizzard more closely reflects the diet and gizzard muscularity of chicks. 
1 Effects of diet and gizzard muscularity on grit use in domestic chickens

2

3 Ryuji Takasaki ${ }^{1,2}$, Yoshitsugu Kobayashi ${ }^{3}$

$4{ }^{1}$ Department of Natural History Sciences, Hokkaido University, Sapporo, Japan

$5 \quad{ }^{2}$ Faculty of Biosphere-Geosphere Science, Okayama University of Science, Okayama, Japan

$6 \quad{ }^{3}$ Hokkaido University Museum, Hokkaido University, Sapporo, Japan

7

8 Corresponding Author

$9 \quad$ Ryuji Takasaki ${ }^{1}$

10 Ridaicho Kitaku Okayama 700-0005 Japan

11 Email address: rtakasaki@big.ous.ac.jp

12 


\section{ABSTRACT}

14 The gizzard is the only gastrointestinal organ for mechanical processing in birds. Many birds use grit in the gizzard to enhance mechanical processing efficiency. We conducted an experiment to test the factors that affect chicken grit use in 68 male layer chicks of Gallus gallus domesticus, which were divided into two different groups in gizzard muscularity (high and low). Within each muscularity group, two different diets were provided (herbivory and non-herbivory) to test whether diet and gizzard muscularity affect grit characteristics including amount, size, and shape (circularity, roundness, and solidity) at different stages of digestion (ingested grit, grit in gizzard, and excreted grit). All animals ingested more grit than they excreted, possibly because excreted grit was below the detection size limit of $0.5 \mathrm{~mm}$ of the present study. The amounts of grit ingested and remained in the gizzard were larger in herbivorous groups, but these groups excreted less grit. Larger, rougher grit was selectively ingested by all chicks, but size preferences were especially pronounced in the herbivorous groups. Grit in the gizzard tended to be larger in herbivorous groups, but the grit in excreta was smaller, whereas the size of excreted grit was larger in groups with less muscular gizzards. Grit in the gizzard was much smoother than the offered and ingested grit, especially in the herbivorous, muscular gizzard groups. Excreted grit in all groups was smoother than the offered grit. These results show that diet affects the characteristics of ingested grit, grit in the gizzard, and excreted grit, whereas gizzard muscularity affects the characteristics of grit in the gizzard and excreted grit. The use of larger sizes and amounts of grit by herbivorous groups may be a response to the needs of digesting hard, coarse materials. The recovered behavioral flexibility of grit use might reflect the omnivorous nature of of grit remaining in the gizzard does not reflect the initial shape of ingested grit, in contrast to previously published ideas. Instead, the shape of grit in the gizzard more closely reflects the diet 
37 and gizzard muscularity of chicks. 


\section{INTRODUCTION}

Digestion, or food processing, is a key phase of animal feeding (Montuelle \& Kane, 2019). In response to the challenges of digestion, many animal lineages have evolved complex morphological and physiological adaptations during their evolutionary history. This is particularly true of birds, which have multiple specialized gastrointestinal organs, including a crop for temporal storage of food (Proctor \& Lynch, 1993), caeca for the conservation of water and/or nitrogen recycling (DeGolier et al., 1999; Karasawa, 1989), and a muscular gizzard for mechanical processing of ingesta (Moore, 1999). In the gizzard, strong compression and translational stress mechanically processes ingesta (Moore, 1998a). Large food particles are selectively retained in the gizzard until these are ground to a small size (Hetland et al., 2003; Moore, 1999). To improve the efficiency of digestion, many birds ingest and retain grit in the gizzard to break down food particles, similar to the use of teeth by non-ruminant mammals (Fritz et al., 2011). Some birds even travel long distances to obtain suitable grit in cases where there are insufficient sands or gravels nearby (Mcllhenny, 1932). Although multiple non-digestive functions such as parasite destruction, relief of hunger, and ballast, have also been proposed for grit use in vertebrates (Wings, 2007), grit use is especially common in herbivorous and granivorous birds (Gionfriddo \& Best, 1999).

The benefits of grit use in domestic chickens have been investigated in poultry science. While grit use is not necessary for survival, previous works generally agree that grit improve digestion efficiency of chickens, especially those fed coarse, less-nutritional food (Fritz, 1937; Hetland et al., 2003; Smith \& MacIntyre, 1959). Additionally, previous works have attempted to identify the best forms and sizes of limestone grit for maximizing egg productivity and quality in layer hens (e.g., Guinotte \& Nys, 1991; Skřivan et al., 2016). Multiple studies have also investigated how different grit characteristics (e.g., size, amount, shape) improve 
62 nutritional/commercial efficiency in domestic chickens (e.g., Balloun \& Phillips, 1956; Cooney,

63 1941). On the other hand, factors that affect grit use behavior are less well understood. This is

64 partly because previous studies are based primarily on grit collected from gizzards (e.g., Best \&

65 Gionfriddo, 1991; Gionfriddo \& Best, 1996), even though initial grit characteristics can be

66 heavily modified through abrasion in the gizzard (Buckner et al., 1926; Wings \& Sander, 2007).

67 Here we test whether differences in diet and gizzard muscularity affect the amount, size, 68 and shape of grit at various stages of digestion. This provides insights into how domestic chicks

69 change grit use behaviour in response to dietary demands.

MATERIALS AND METHODS

72 Ethics statement: The experiment in this study was approved by Hokkaido University

73 (Permission number: 16-0023) in Sapporo, Japan, and followed the rules specified in the Hokkaido University manual for implementing animal experimentation.

\section{Experimental design and managements}

A total of 68 one-day-old male layer chicks (Gallus gallus domesticus), purchased from

a local feed manufacturer, were used in this experiment. This sample size was set based on Hokkaido University regulations, space availability, and several prior experiments conducted on domestic chickens (Hetland et al., 2003; Van der Meulen et al., 2008). Prior to the experiment, the chicks were raised for three weeks to produce two groups of differing gizzard muscularity

82 (evaluated as the relative weight of a gizzard to the body mass of the chick). This interval was

83 determined based on the study of Amerah et al. (2007), which demonstrated a significant

84 difference in gizzard muscularity at three weeks. For three weeks, all chicks were fed a commercial starter pellet (Yamaichi Shiryo Co. Ltd.). Muscular development of the gizzard (Fig. 
86 S1) was enhanced in half of the chicks (34 individuals) by increasing the amount of insoluble

87 fiber in the diet (Sacranie et al., 2012). To accomplish this, rice hulls ground to $<5 \mathrm{~mm}$ (Hondo

88 Co. Ltd.) were mixed ( $30 \%$ by weight) with the starter pellet. The chicks had ad libitum access to

89 feed and water.

90 The experiment was conducted for one week on four groups varying in diet and gizzard

91 muscularity (17 individuals each): a non-herbivorous diet with a muscular gizzard (nH-M), an

92 herbivorous diet with a muscular gizzard (H-M), a non-herbivorous diet with a less-muscular

93 gizzard (nH-1M), and an herbivorous diet with a less-muscular gizzard (H-1M). Herbivorous

94 groups (H-M and H-lM) were fed a mixture of Poaceae (Medicago sativa) and Fabaceae (Phleum

95 pratense) grasses, both purchased from Mapet Cor $=$ Non-herbivorous groups (nH-M and $\mathrm{nH}-$

$96 \mathrm{MM}$ ) were fed dried fish (Engraulis japonicas), purchased from Sakamoto Cor $\cdots$ ' The chicks were

97 fed either $100 \%$ grass or $100 \%$ fish to test the effect of diet on grit use under extreme dietary

98 differences. Grass, and dried fish were ground to $<5 \mathrm{~mm}$ and provided as meal.

99 During the experiment, all chicks were raised in individual cages with a wire mesh

100 floor. Room temperature was maintained between $28-30{ }^{\circ} \mathrm{C}$. Lighting was controlled to provide

101 a 12-hour light/dark cycle. All of the chicks were given ad libitum access to a total of 24 grams

102 of grit per chick, which was provided separately from the feed. Feces were collected on the last

103 day of the experiment to evaluate the characteristics of excreted grit. All chicks were weighed

104 and then euthanized by cervical dislocation at the end of the experiment, following Hokkaido

105 University regulations. The gizzard was removed from each of the carcasses and weighed after

106 removing stomach contents.

107

108 Terminology

109 We use the term offered grit to refer to all of the stones which were given with $a d$ 
110 libitum access to the chicks (Fig. 1A). Uningested grit refers to the grains that were not ingested

111 by the chicks from the offered grit by the end of the experiment (i.e. the remainder of the offered

112 grit). Ingested grit refers to the grains that were selected and swallowed by the chicks from the

113 offered grit during the experiment; this was measured as the difference between the offered and

114 the uningested grit fractions. Grit in the gizzard refers to the particles remaining in the gizzards

115 of the chicks after euthanasia. Excreted grit refers to the particles excreted with the feces on the

116 last day of the experiment. Initial gizzard muscularity refers to the gizzard muscularity of chicks

117 at the start of the experiment. "Rough" is used to describe grit with relatively low circularity,

118 roundness, and/or solidity, and "smooth" is used to describe grit with relatively high shape index.

\section{Grit characteristics}

121 All of the grit grains used in the experiment were commercial quartzite stones. The

122 amount, size, and shape of grit at different stages of digestion (i.e. offered grit, uningested grit,

123 grit in the gizzard, and excreted grit) were evaluated. The amount of grit was weighed in grams.

124 Size and shape were evaluated quantitatively in ImageJ using the menu command Analyze >

125 Analyze Particles (Schneider et al., 2012). To obtain the images for these analyses, grains were

126 manually separated and backlit to obtain clear outlines (Fig. 1B, Fig. 2). All images were taken

127 manually. The minor axis of a particle was used to measure grit size (in millimeters), and the

128 minimum size threshold for collection was $0.5 \mathrm{~mm}$ (i.e., grit particles $<0.5 \mathrm{~mm}$ were not

129 retrieved). Circularity, roundness, and solidity were employed as grit shape indices (Schneider et

130 al., 2012). Circularity was calculated as four times the product of $\pi$ and area, divided by the

131 square of the perimeter. Roundness was taken from the inverse of the aspect ratio. Solidity was

132 calculated as the area of a grain divided by the area of the convex hull (Fig. 1C). The quantitative

133 grit shape evaluation methods used here are not direct equivalents of the qualitative grit shape 
134 evaluation proposed by Best \& Gionfriddo (1991). For example, the quantitative methods are

135 less powerful in detecting corner sharpness, whereas the qualitative methods do not take aspect

136 ratio into account. Despite the differences, both methods adequately evaluate grit shape and this

137 study adopts the quantitative method for scientific objectivity.

138

139 Offered grit

140 The amount, size, and shape of ingested grit were inferred by comparing the

141 characteristics of offered and uningested grit. These measurements were performed on a group-

142 by-group basis. To test grit size preference of the chicks, the size distribution of offered grit was

143 controlled in advance. Grit was classified into six different size classes by dry sieving using

144 mesh sieves (Sanpo Corp.; 0.5-1.0 mm, 1.0-1.4 mm, 1.4-1.7 mm, 1.7-2.0 mm, 2.0-2.8 mm,

$1452.8-3.35 \mathrm{~mm}$ ). Four grams of grit from each size class were supplied in the mixture. Before the

146 experiment, minor axis, circularity, roundness, and solidity of 500 randomly chosen grit from

147 each grit size class were evaluated using ImageJ (Fig. S2). After the experiment, uningested grit

148 was collected and sieved again into the six size classes. Five-hundred uningested grit were

149 randomly sampled from each size classes and their size and shape indices were evaluated (Fig.

150 S2). Because the weight of the 500 randomly-selected grit of each size category was not

151 determined, the total number of grit per size class could not be reconstructed, and therefore the

152 average particle size of offered and uningested grit is unavailable. To test size preferences, the

153 amount of ingested grit in each size class was measured as the difference between the weights of

154 the uningested grit and the weights of the offered grit, by size class (4 grams each). Average

155 shape indices of the uningested grit were compared to those of the offered grit to test if there was

156 any shape preference in the ingested grit. The amounts, sizes, and shapes of the uningested grit

157 were then compared among different dietary and gizzard muscularity groups. 
159 Grit in the gizzard

160 Grit in the gizzard was separated from other stomach contents using a flotation method

161 (decantation) modified from Itani (2015). Stomach contents were soaked in water in a beaker

162 overnight. Gizzard digesta was stirred and then low-density floating food particles were gently

163 discarded. This procedure was repeated until only grit remained in the beaker. Grit smaller than

$1640.5 \mathrm{~mm}$ were collected if possible, but were removed from the analyses. The total amount of grit

165 was weighed, and then the size and shape of all grit particles in the gizzard were analyzed using

166 ImageJ (Fig. S2). The amounts, sizes, and shapes of the gizzard grit were compared among

167 different dietary and gizzard muscularity groups.

168

169

Excreted grit

170 Excreted grit was collected and evaluated on a group basis. Grit particles were separated

171 from fecal particles using the same decantation method as for separating gizzard grit. Grit

172 smaller than $0.5 \mathrm{~mm}$ were collected if possible, but were removed from the analyses. The total

173 amount of grit was weighed and the sizes and shapes of all excreted grit were analyzed using

174 ImageJ (Fig. S2). The amounts, sizes, and shapes of the excreted grit were evaluated and

175 compared with those of the gizzard grit. Grit characteristics were also compared among different

176 diet and gizzard muscularity groups. Because excreted grit was only collected on the last day of

177 the experiment, and because it was collected per group instead of per individual, the amount and

178 size of excreted grit per individual is unavailable in the present study.

179

180 Statistical analyses

181

All statistical analyses were conducted using R software package (R Core Team, 2019). 
182 Because some of the datasets did not have a normal distribution, non-parametric analyses were

183 conducted throughout. Ordinal logistic regressions were conducted as a non-parametric

184 equivalent of two-way ANOVA to test the effects of gizzard muscularity, diet, and their

185 interactions for body mass, gizzard mass, and grit features (size, amount, and shape), using the R

186 package MASS (Venables \& Ripley, 2013). The Steel-Dwass method was used for post-hoc

187 tests. Correlations between shape indices of gizzard grit and gizzard muscularity at the end of the

188 experiment were tested using Spearman's rank correlation. Grit amount was corrected using

189 chick body mass and grit size was corrected using the cubic root of chick body mass in the

190 analyses. Average chick body mass and grit amount were compared on an individual basis (the

191 average of individuals per group), whereas average grit size, circularity, roundness, and solidity

192 were compared on grit basis (the average of the grits in each group).

193 Chicks that were euthanized before the end of the experiment following Hokkaido

194 University regulations were excluded from the analyses. The data analyzed are provided as

195 Supplemental Information (Data S1-S6).

196

197 RESULTS

198 During the experiment, two chicks from the non-herbivorous, muscular gizzard group

199 (nH-M), one chick from the non-herbivorous, less-muscular gizzard group (nH-1M), five chicks

200 from the herbivorous, muscular gizzard group (H-M), and two chicks from the herbivorous, less-

201 muscular gizzard group (H-lM) were euthanized before the end of the experiment due to a

202 sudden drop in body mass, following Hokkaido University regulations. Therefore, the analyses

203 were performed on a total of 58 chicks.

204 The average body mass of the chicks at the end of the experiment was affected by both

205 diet and initial gizzard muscularity, as well as the interaction of these factors (Table S1). Body

Peer] reviewing PDF | (2020:03:46973:2:0:NEW 25 Sep 2020) 
206 masses were higher in the non-herbivorous groups than in the herbivorous groups (nH-M $>H-M$,

$207 \mathrm{nH}-1 \mathrm{M}>\mathrm{H}-\mathrm{lM}$; Table 1, Table S2). This difference in body mass was significant only between

208 the groups with high initial gizzard muscularity. Average gizzard muscularity at the end of the

209 experiment was affected by diet and initial gizzard muscularity (Table S1). The average gizzard

210 muscularity was significantly higher in herbivorous groups than in non-herbivorous groups (H-M

$211>\mathrm{nH}-\mathrm{M}, \mathrm{H}-\mathrm{lM}>\mathrm{nH}-\mathrm{lM}$; Table S2). While the differences in initial gizzard muscularity

212 remained significant between the herbivorous groups at the end of the experiment $(\mathrm{H}-\mathrm{M}>\mathrm{H}-$

$213 \mathrm{lM}$ ), the differences were insignificant between the non-herbivorous groups. This result is likely

214 to reflect a rapid change in gizzard muscularity associated with diet change.

215

\section{Grit amount}

The experiment demonstrated that amount of ingested grit per chick was approximately

$2183 \mathrm{~g}$ in av erage ( $1.7 \%$ of body mass), whereas the amount of grit in the gizzard was approximately

$2191 \mathrm{~g}$ in average $(0.5 \% \text { of body mass })_{2}$ suggesting that about two-thirds of the ingested stones were excreted during the experiment (Table 1). The amount of excreted grit on the last day of the experiment was $0.045 \mathrm{~g}$ per chick, on average. Diet affected the average amount of ingested grit and grit in the gizzard, both in total and relative to body mass (Tabl $=\mathrm{Sl})$. The post-hoc tests $>\mathrm{nH}-\mathrm{M}, \mathrm{H}-\mathrm{lM}>\mathrm{nH}-\mathrm{lM}$; Table S2). The amount of grit in the gizzard relative to body mass was also greater in herbivorous groups $(\mathrm{H}-\mathrm{M}>\mathrm{nH}-\mathrm{M}, \mathrm{H}-\mathrm{lM}>\mathrm{nH}-\mathrm{lM}$; Table S2). No significant difference in the amount of ingested grit and grit in the gizzard was detected between groups with differing initial gizzard muscularity. The amount of excreted grit on the last day of the experiment was larger in non-herbivorous groups than in herbivorous groups in total weights 
230 available to test its significance ( $\mathrm{n}=1$ per group).

231

\section{Grit size}

233

Large grit $(>2.8 \mathrm{~mm})$ were generally ingested more than smaller grit (Fig. 3, Table S3).

234 The average size of grit in the gizzard was about $1.84 \mathrm{~mm}$ and that of the excreted grit was 1.09

$235 \mathrm{~mm}$ (Table 1). Diet affected the ingestion of grit larger than $1.4 \mathrm{~mm}$ (Table S4). Post-hoc tests

236 show that this difference was significant between herbivorous and non-herbivorous groups of the

237 less-muscular gizzard group $(\mathrm{H}-1 \mathrm{M}>\mathrm{nH}-\mathrm{lM}$; Table S5). Diet and the interaction of gizzard

238 muscularity with diet affected the average size of grit in gizzard relative to body mass (Table

239 S1). While the average absolute sizes of the grit in the gizzard were larger in non-herbivorous

240 groups, the average sizes of grit in the gizzard relative to body mass were significantly larger in

241 herbivorous groups (Table 1, Table S2). Within non-herbivorous groups, the less-muscular

242 gizzard group contained significantly larger grit in the gizzard relative to their body mass than

243 the muscular gizzard group (nH-1M > nH-M; Table 1, Table S2). The average size of excreted

244 grit was affected by diet and the interaction of diet and gizzard muscularity (Table S1). Within

245 the less-muscular gizzard group, excreted grit was larger in the non-herbivorous chicks than in

246 the herbivorous chicks $(\mathrm{nH}-\mathrm{lM}>\mathrm{H}-\mathrm{lM}$; Table S2). Furthermore, excreted grit was larger in the

247 non-herbivorous, less-muscular group compared to the non-herbivorous, muscular group (nH-lM $248>$ nH-M, Table S2), both in absolute and corrected values.

250 Grit shape

251 Circularity, roundness, and solidity of the uningested grit was higher than that of the

252 offered grit (Fig. 4A, Table 2), suggesting that ingested grit had low circularity, roundness, and 253 solidity. This trend in circularity and solidity is generally significant for grit larger than $1.4 \mathrm{~mm}$ 
254 (Table S6). Grit in the gizzard had higher circularity, roundness, and solidity than both the

255 offered and uningested grit (Table 2). This trend in circularity and solidity was significant for all

256 size classes and the trend in roundness was generally significant for herbivorous groups (Table

257 S7). The circularity and solidity of excreted grit were higher than those of grit in the gizzard

258 (Table 2), although this trend is only significant for solidity (Table S8). The shape indices of

259 excreted grit were higher than those of the offered grit (generally significant for circularity and

260 roundness; Table $\mathrm{S} 8$ ).

$261 \quad$ Neither diet nor gizzard muscularity strongly affected shape indices of the uningested

262 grit (Table S9, S10). Diet and gizzard muscularity did affect the circularity of the grit in the

263 gizzard of nearly all grit size classes, while diet, gizzard muscularity, and their interaction

264 affected the solidity of grit in gizzard (Fig. 4B, Table S11). On the other hand, the roundness of

265 grit in the gizzard was affected only by diet in size classes $1.0-2.0 \mathrm{~mm}$. Post-hoc tests show that

266 grit in the gizzard of herbivorous groups was significantly higher in circularity and solidity for

267 most size classes (H-M >nH-M, H-lM >nH-lM; Fig. 4B, Table S12). Circularity and solidity of

268 the grit in the gizzard were also higher in the herbivorous, muscular gizzard group than in the

269 herbivorous, less-muscular gizzard group (H-M > H-lM; Table S12). Circularity, roundness, and

270 solidity were correlated with gizzard muscularity $(\mathrm{p}<0.05)$. The solidity of excreted grit is

271 inferred to be affected by diet and the interaction of gizzard muscularity and diet (Table S13),

272 although the difference was undetected in post-hoc tests (Table S14).

273

274 DISCUSSION

275 Grit amount

276 The larger amounts of ingested grit and grit in the gizzard in herbivorous groups (H-lM >

$277 \mathrm{nH}-\mathrm{lM}$; Tables S2, S3) are concordant with previous studies (see a comprehensive review by 
278 Gionfriddo and Best, 1999). The larger amount of excreted grit in the non-herbivorous groups

279 (nH-M $>$ H-M, nH-lM $>$ H-lM) might suggest that the large amount of grit in the gizzard in

280 herbivorous groups was driven by higher ingestion rates of grit in combination with limited grit

281 excretions. Retaining a larger amount of grit in the gizzard is likely to benefit herbivorous groups

282 by helping to break down tough grass, fibers, because a larger amount of grit in the gizzard

283 improves digestive performance in domestic chickens (Bale-Therik et al., 2012), as long as the

284 amount is not excessive (Moore, 1998b).

285 Assuming equivalent intake and excretion of grit, the total weight of grit theoretically

286 excreted throughout the experiment would be $20.99 \mathrm{~g}, 30.46 \mathrm{~g}, 17.58 \mathrm{~g}$, and $53.22 \mathrm{~g}$ in groups

287 nH-M, H-M, nH-lM, and H-lM, respectively. However, these values are higher than the

288 measured amounts of grit excreted. Reasonable explanations for this are that the chicks excreted

289 more grit on days prior to fecal collection, or that a high proportion of the excreted grains were

290 less than $0.5 \mathrm{~mm}$ in size and were therefore undetected. While both are likely, the latter

291 explanation suggests that up to $20.36 \mathrm{~g}, 28.64 \mathrm{~g}, 8.20 \mathrm{~g}$, and $47.42 \mathrm{~g}$ of grit in groups $\mathrm{nH}-\mathrm{M}, \mathrm{H}-$

$292 \mathrm{M}, \mathrm{nH}-\mathrm{lM}$, and $\mathrm{H}-\mathrm{lM}$, respectively, were abraded to less than $0.5 \mathrm{~mm}$. The larger amount of lost

293 grit in herbivorous groups $(\mathrm{H}-\mathrm{M}>\mathrm{nH}-\mathrm{M}, \mathrm{H}-\mathrm{lM}>\mathrm{nH}-\mathrm{lM})$ might indicate a more thorough

294 particle size reduction of grit due to more extensive use in the herbivorous groups. This would

295 result in a larger fraction of the grit being excreted at sizes below the detection limit of the

296 present study. The fact that, on average, larger grains were excreted by the non-herbivorous

297 group with less muscular gizzards supports this latter interpretation. However, a more specific

298 experiment with specific daily records on the amount of excreted grit would be required to make 299 any further conclusions.

301 Grit size 
Because the size of grit in the gizzard is unlikely to affect digestion efficiency in

303 domestic chickens (Smith, 1960), and larger grit may even be associated with lower digestion

304 efficiency (Moore, 1998c), selective ingestion of larger grit in all groups (Table S3) may simply

305 reflect the ease of picking larger grains. The smaller size of the excreted grit than the grit in the

306 gizzard (Table S8) in all groups suggests that size is one of the primary factors that determines

307 which grains are to be excreted in domestic chickens. While the excretion of small grit is

308 concordant with a trend in domestic chickens (Smith, 1960), it contrasts with a trend reported in

309 House Sparrows Passer domesticus (Gionfriddo \& Best, 1995). Therefore, the responses in the

310 size of excreted grit may vary taxonomically. The larger sizes of ingested grit and grit in the

311 gizzard (relative to body mass) in herbivorous groups (Fig. 3, Tables 1, S2, S5) agree with

312 previous works (Gionfriddo \& Best, 1999; Hoskin et al., 1970; May \& Braun, 1973; Norris et al.,

313 1975; Soler et al., 1993; Thomas et al., 1977). The large size of excreted grit in the non-

314 herbivorous, less-muscular gizzard group (Table 1) suggests that this group either could not

315 retain grit in the gizzard or did not use the grit as extensively, thus failing to reduce its size. Both

316 possibilities are consistent with the large amount of excreted grit measuring greater than $0.5 \mathrm{~mm}$

317 in this group.

318

319 Grit shape and abrasions

320 The higher average roughness of the ingested grit (having higher shape indexes) than

321 the offered grit (Fig. 4A, Table S6) is consistent with previous knowledge in domestic chickens

322 (Smith, 1960) as well as in House Sparrows Passer domesticus and the Northern Bobwhite

323 Colinus virginianus (Best \& Gionfriddo, 1994). Moore (1998c) showed that rough grit may

324 increase comminution efficiency. Therefore, in each group, actively ingesting rough grit may

325 reflect a congenital behavior for better digestion efficiency, although further investigation into 
326 the impacts of grit shape on comminution efficiency is necessary. That the grit in the gizzard is

327 smoother on average than the offered grit (Table S7) contrasts the selective ingestion of rougher

328 grit. Because the excreted grit was also smoother than the offered grit (Table S8), it is most

329 likely that the grit in the gizzard was severely abraded inside the gizzard (Wings \& Sander,

330 2007). Severe grit abrasion and the associated grain size reduction are both concordant with a

331 large amount of lost grit (see above).

332 The dominance of smooth grit in the gizzard of herbivorous groups, as well as in the

333 more muscular gizzard groups $(\mathrm{H}-\mathrm{M}>\mathrm{nH}-\mathrm{M}, \mathrm{H}-\mathrm{lM}>\mathrm{nH}-\mathrm{lM}, \mathrm{H}-\mathrm{M}>\mathrm{H}-\mathrm{lM}$; Fig. 4B, Table

334 S12), strongly suggests that diet and gizzard muscularity affect the degree of abrasion of grit in

335 the gizzard. Because dietary structures significantly affect gizzard muscularity in birds, including

336 domestic chickens (Dekinga et al., 2001; Hetland et al., 2003; Sacranie et al., 2012), gizzard

337 muscularity may be a primary factor in determining the degree of abrasion of grit in the gizzard.

338 Correlations between gizzard muscularity and shape indices of grit in the gizzard are also

339 consistent with this interpretation. Therefore, the shapes of particles in the gizzard are unlikely to

340 fully reflect grit selection patterns in domestic chickens, in contrast to previously published

341 concepts (Best \& Gionfriddo, 1991; Gionfriddo \& Best, 1996). Instead, our experiment suggests

342 that the differences in the shapes of grains in the gizzard more strongly reflect differences in

343 diets and gizzard muscularity. At the same time, however, it should be noted that in cases where

344 birds can only access smoother stones for use as grit in natural conditions, grit might be expected

345 to be less abraded in the gizzard and may thus more strongly reflect the original shape.

346 Investigations using broader taxonomic datasets based on wild birds would be expected to

347 provide further insights.

349 Chick grit use behaviors 
This study is the first attempt to examine whether diet and gizzard muscularity affect

351 chicken grit use behaviors throughout ingestion, retention, and excretion. This experiment

352 strongly suggests that, under the experimental conditions used here, grit characteristics were

353 primarily affected by diet and secondarily by the muscularity of the gizzard (Fig. 5, Table 1,2).

354 The flexibility of grit use in response to the needs of digesting tough, coarse ingesta may reflect

355 the omnivorous nature of Gallus gallus domesticus and might facilitate easy shifts between

356 herbivorous and carnivorous diets. Because numerous other bird species are known to be

357 omnivorous and experience seasonal diet shifts (e.g., del Hoyo et al., 2005), flexibility in the use

358 of grit in the gizzard may not be limited to domestic chickens. Rather, it might be common, and

359 may support the wide dietary range of omnivorous birds, together with phenotypic flexibility of

360 the gizzard (Dekinga et al., 2001; Starck, 1999; van Gils et al., 2005). Further studies on other

361 birds are required to test this hypothesis.

362

\section{CONCLUSION}

This experiment on chick grit use behaviors demonstrated that diet and gizzard

365 muscularity affect the size, amount, and the shape of ingested and excreted grit. It also revealed

366 that grit in the gizzard was greatly modified through abrasion; therefore, grit did not retain its

367 original sizes nor shapes upon ingestion. Instead, gizzard grit shapes reflected gizzard activity, as

368 determined by chick diet and gizzard muscularity: roughest in the chicks with less-muscular

369 gizzards on a non-herbivorous diet and smoothest in the chicks with muscular gizzards on a

370 herbivorous diet. Selective ingestion of rough grit regardless of diet and gizzard muscularity is

371 likely an innate selective behavior. On the other hand, the ingestion of a larger amount of grit by

372 the herbivorous groups may be a behavioral adaptation to ensure an adequate supply of grit as it

373 is abraded during the course of the grinding action of coarse ingesta. The flexibility of grit use by 
374 individuals of a different diet, which is expected to reflect gizzard activity, may reflect the

375 omnivorous nature of chickens, and possibly facilitate their seasonal diet shifts in nature.

376

377 ACKNOWLEDGEMENTS

378 We thank Y. Deguchi and F. Kobari for allowing access to the experimental rooms and

379 loan of experimental equipment, and T. Matsushima to detailed advice on chick management and

380 experimental designs. The first author greatly appreciates T. Tanaka for helping out conducting

381 the experiment. We also thank K. Inada, M. Iijima, Junki Yoshida, Chinzorig Tsogtbaatar, and

382 A. R. Fiorillo for their helpful discussions and valuable insights. Finally, we appleciate G.

383 Funston for reviewing and editing the language, clarity, and style of the manuscript. 


\section{REFERENCES}

386 Amerah AM, Lentle RG, and Ravindran V. 2007. Influence of feed form on gizzard morphology and particle size spectra of duodenal digesta in broiler chickens. The Journal of Poultry Science 44:175-181.

Bale-Therik JF, Sabuna C, and Jusoff K. 2012. Influence of grit on performance of local chicken under intensive management system. Global Veterinaria 9:248-251.

Balloun SL, and Phillips RE. 1956. Grit feeding affects growth and feed utilization of chicks and egg production of laying hens. Poultry Science 35:566-569.

Best LB, and Gionfriddo JP. 1991. Characterization of grit use by cornfield birds. Wilson Bulletin 103:68-82.

Best LB, and Gionfriddo JP. 1994. Effects of surface texture and shape on grit selection by house sparrows and northern bobwhite. The Wilson Bulletin:689-695.

397 Buckner GD, Martin JH, and Peter A. 1926. Concerning the gowth of chickens raised without grit. Poultry Science 5:203-208.

Cooney WT. 1941. Influence of various grits on battery-raised broilers. Station circular / Agricultural Experiment Station / Oregon State Agricultural College 139.

401 DeGolier TF, Mahoney SA, and Duke GE. 1999. Relationships of avian cecal lengths to food habits, taxonomic position, and intestinal lengths. The Condor 101:622-634. 
403 Dekinga A, Dietz MW, Koolhaas A, and Piersma T. 2001. Time course and reversibility of

404 changes in the gizzards of red knots alternately eating hard and soft food. Journal of

$405 \quad$ Experimental Biology 204:2167-2173.

406 del Hoyo J, Elliott A, and Christie D. 2005. Handbook of the Birds of the World. Volume1:

407 Cuckoo-shrikes to Thrushes. Barcelona: Lynx Edicions.

408 Fritz J, Kienzle E, Hummel J, Wings O, Streich WJ, and Clauss M. 2011. Gizzard vs. teeth, it's a

409 tie: food-processing efficiency in herbivorous birds and mammals and implications for

$410 \quad$ dinosaur feeding strategies. Paleobiology 37:577-586.

411 Fritz JC. 1937. The effect of feeding grit on digestibility in the domestic fowl. Poultry Science

412 $16: 75-79$.

413 Gionfriddo JP, and Best LB. 1995. Grit use by house sparrows - effects of diet and grit size. Condor 97:57-67.

415 Gionfriddo JP, and Best LB. 1996. Grit-use patterns in North American birds: the influence of 416 diet, body size, and gender. The Wilson Bulletin:685-696.

417 Gionfriddo JP, and Best LB. 1999. Grit use by birds: a review. In: Nolan Jr. V, Ketterson ED, and Thompson CF, eds. Current Ornithology. New York: Kluwer Academic/Plenum Publishers, 89-148.

420 Guinotte F, and Nys Y. 1991. Effects of particle size and origin of calcium sources on eggshell 
quality and bone mineralization in egg laying hens. Poultry Science 70:583-592.

422 Hetland H, Svihus B, and Krogdahl A. 2003. Effects of oat hulls and wood shavings on digestion in broilers and layers fed diets based on whole or ground wheat. British Poultry Science 44:275-282.

Hoskin CM, Guthrie RD, and Hoffman BL. 1970. Pleistocene, Holocene and recent bird gastroliths from interior Alaska. Arctic:14-23.

427

428

Itani K. 2015. Eating patterns of broiler chickens fed insoluble grit and its effect on intake variation, retention time, performance and gizzard development Master. Norwegian University of Life Sciences.

Karasawa Y. 1989. Ammonia production from uric acid, urea, and amino acids and its absorption from the ceca of the cockerel. Journal of Experimental Zoology Supplement 3:75-80.

May TA, and Braun CE. 1973. Gizzard stones from adult white-tailed ptarmigan (Lagopus leucurus) in Colorado. Arctic and Alpine Research:49-57.

Mcllhenny E. 1932. The blue goose in its winter home. The Auk 49:279-306.

Montuelle SJ, and Kane EA. 2019. Food capture in vertebrates: a complex integrative performance of the cranial and postcranial systems. In: Bels V, and Whishaw IQ, eds. Feeding in Vertebrates: Evolution, Morphology, Behavior, Biomechanics. Cham: Springer International Publishing, 71-137. 
439 Moore S. 1998a. The gizzard morphology of an avian herbivore: the domestic goose, Anser anser. Australian Journal of Zoology 46:345-357.

441 Moore SJ. 1998b. The comparative functional gizzard morphology of several species of birds. Australian Journal of Zoology 46:359.

Moore SJ. 1998c. Use of an artificial gizzard to investigate the effect of grit on the breakdown of grass. Journal of Zoology 246:119-124.

Moore SJ. 1999. Food breakdown in an avian herbivore: who needs teeth? Australian Journal of Zoology 47:625.

Norris E, Norris C, and Steen JB. 1975. Regulation and grinding ability of grit in the gizzard of Norwegian willow ptarmigan (Lagopus Lagopus). Poultry Science 54:1839-1843. University Press.

R Core Team. 2019. R: A language and environment for statistical computing. Vienna, Austria: R Foundation for Statistical Computing. fiber and intermittent feeding on gizzard development, gut motility, and performance of broiler chickens. Poult Sci 91:693-700.

456 Schneider CA, Rasband WS, and Eliceiri KW. 2012. NIH Image to ImageJ: 25 years of image 
analysis. Nature Methods 9:671-675.

458 Skřivan M, Englmaierová M, Marounek M, Skřivanová V, Taubner T, and Vít T. 2016. Effect of

463

464

465

466

467

468

470

471

472

473

474 performance and eggshell quality of hens. Czech Journal of Animal Science 61:473-480.

461 Smith R. 1960. The influence of size and surface condition of grit upon the digestibility of feed by the domestic fowl. Canadian Journal of Animal Science 40:51-56.

dietary magnesium, calcium, phosphorus, and limestone grain size on productive

Smith R, and MacIntyre T. 1959. The influence of soluble and insoluble grit upon the digestibility of feed by the domestic fowl. Canadian Journal of Animal Science 39:164169.

Soler JJ, Soler M, and Martinez JG. 1993. Grit ingestion and cereal consumption in five corvid species. ARDEA-WAGENINGEN- 81:143-143.

Starck JM. 1999. Phenotypic flexibility of the avian gizzard: rapid, reversible and repeated changes of organ size in response to changes in dietary fibre content. Journal of Experimental Biology 202:3171-3179.

Thomas G, Owen M, and Richards P. 1977. Grit in waterfowl at the Ouse Washes, England. Wildfowl 28:3.

Van der Meulen J, Kwakernaak C, and Kan CA. 2008. Sand intake by laying hens and its effect on egg production parameters. J Anim Physiol Anim Nutr (Berl) 92:426-431.

Peer] reviewing PDF | (2020:03:46973:2:0:NEW 25 Sep 2020) 
475 van Gils JA, Battley PF, Piersma T, and Drent R. 2005. Reinterpretation of gizzard sizes of red

476 knots world-wide emphasises overriding importance of prey quality at migratory stopover

477 sites. Proc Biol Sci 272:2609-2618.

478 Venables WN, and Ripley BD. 2013. Modern applied statistics with S: Springer Science \&

$479 \quad$ Business Media.

480 Wings O. 2007. A review of gastrolith function with implications for fossil vertebrates and a

$481 \quad$ revised classification. Acta Palaeontologica Polonica 52.

482 Wings O, and Sander PM. 2007. No gastric mill in sauropod dinosaurs: new evidence from

483 analysis of gastrolith mass and function in ostriches. Proceedings of the Royal Society B:

$484 \quad$ Biological Sciences 274:635-640.

485

486

487 
Figure 1

Visualized experimental design.

(A) Terminology regarding grit treated in this study. (B) Grit shape evaluation procedure. (C) Schematic explanation of grit shape indexes.
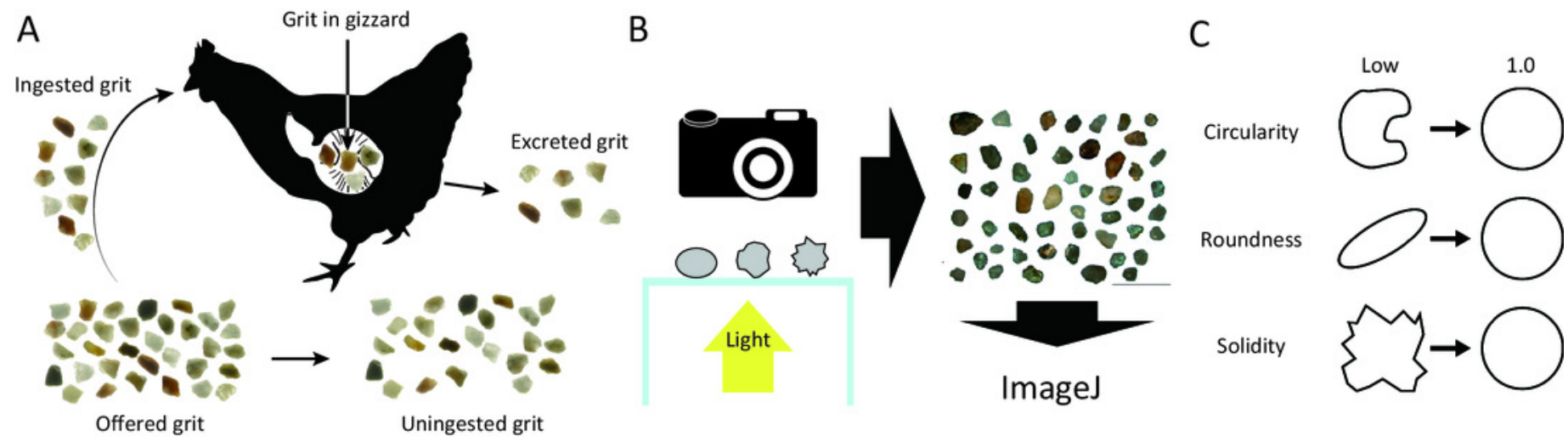


\section{Figure 2}

Representatives offered grit, uningested grit, grit in the gizzard, and excreted grit.

Note that the grit shown here are only few representatives from hundreds of grit therefore they may not reflect true size/shape distribution. Abbreviations: $\mathrm{H}-\mathrm{IM}$, herbivorous diet with a less-muscular gizzard; $\mathrm{H}-\mathrm{M}$, herbivorous diet with a muscular gizzard; $\mathrm{nH}-\mathrm{IM}$, non-herbivorous diet with a less-muscular gizzard; $\mathrm{nH}-\mathrm{M}$, non-herbivorous diet with a muscular gizzard. Scale $=50 \mathrm{~mm}$.
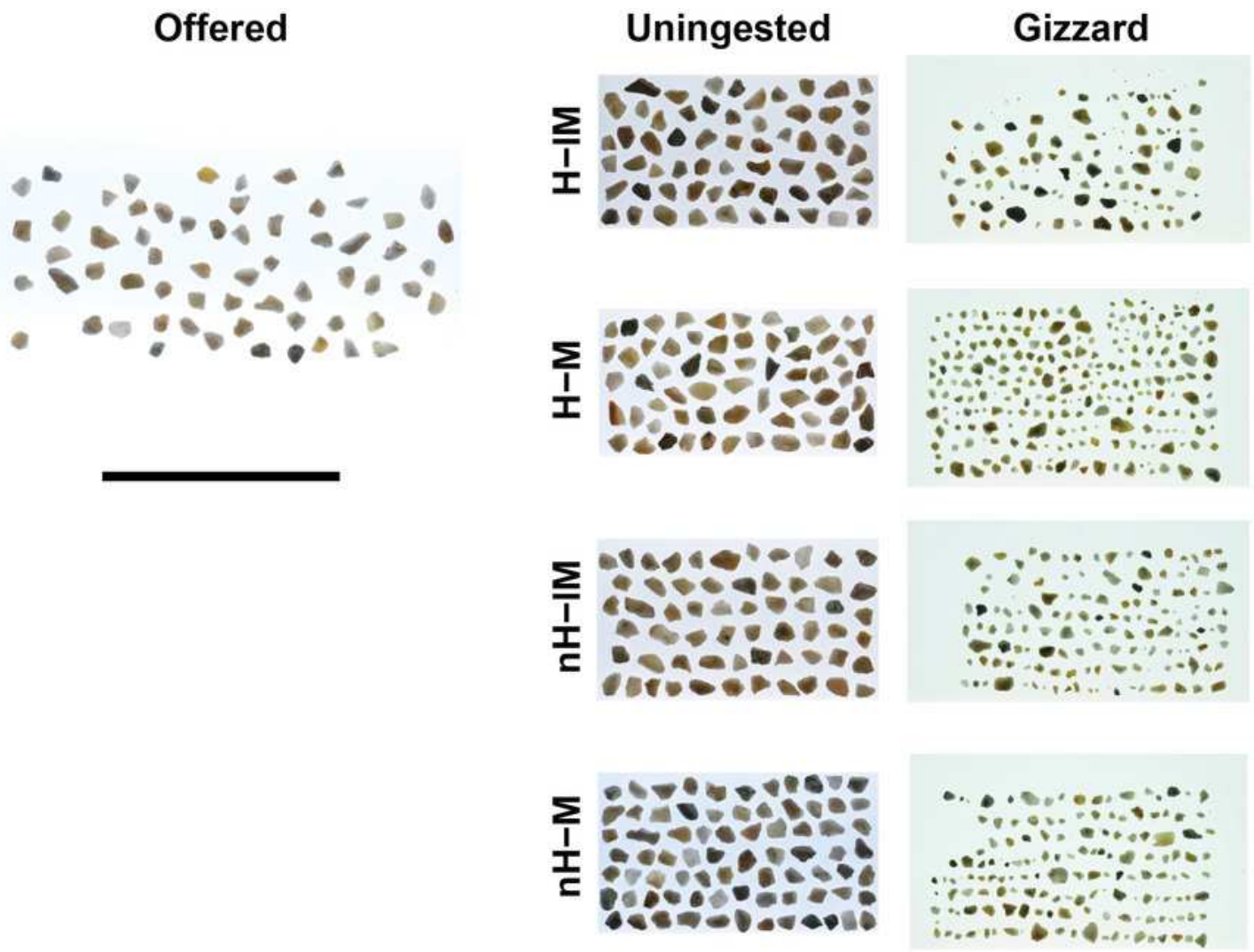

\section{Excreted}
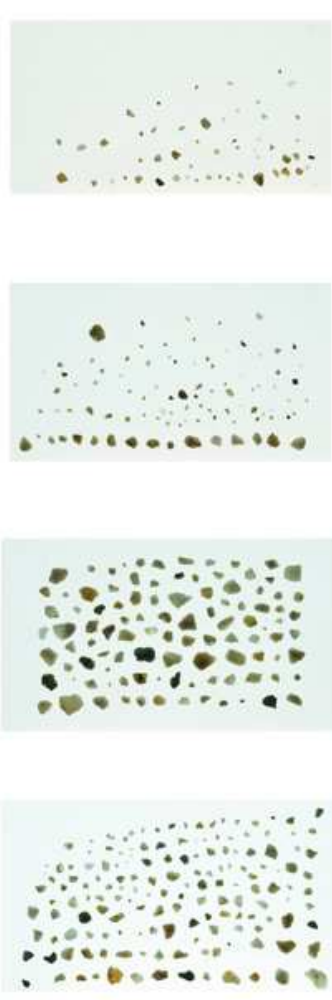
Figure 3

Boxplots showing the amount of ingested grit by experimental groups, shown per grit size categories.

The brackets represent significant differences at $\mathrm{p}<0.05$. Abbreviations: $\mathrm{H}-\mathrm{IM}$, herbivorous diet with a less-muscular gizzard; H-M, herbivorous diet with a muscular gizzard; $\mathrm{nH}-\mathrm{IM}$, nonherbivorous diet with a less-muscular gizzard; nH-M, non-herbivorous diet with a muscular gizzard.

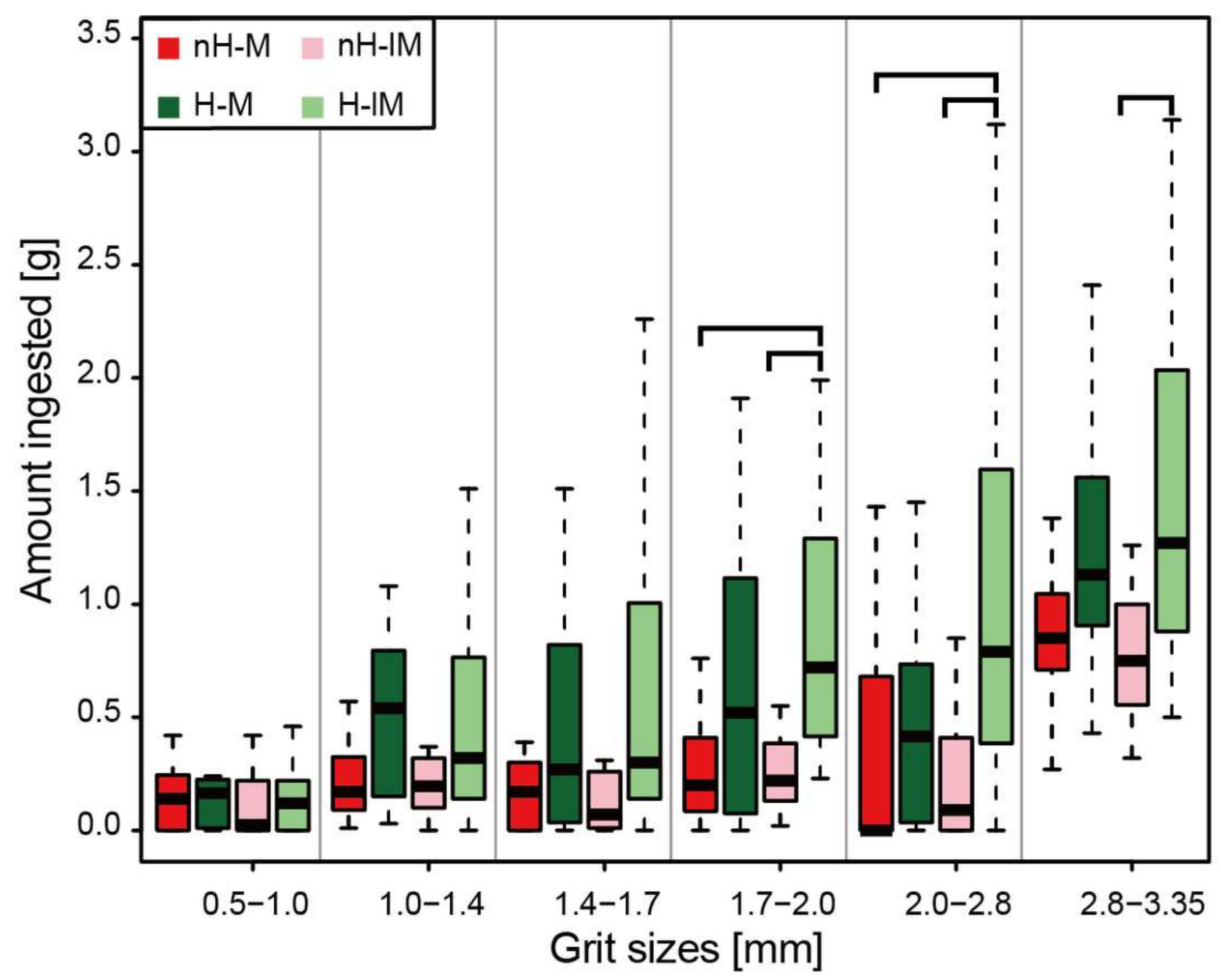




\section{Figure 4}

Boxplots comparing grit shapes.

(A) Boxplots comparing shapes of the initial grits and the remained grits by each

experimental group, shown per grit size categories. (B) Boxplots comparing shapes of the grit in the gizzard by the experimental groups, shown per grit size categories. The brackets represent significant differences at $\mathrm{p}<0.05$. Abbreviations: $\mathrm{H}-\mathrm{IM}$, herbivorous diet with a less-muscular gizzard; H-M, herbivorous diet with a muscular gizzard; $\mathrm{nH}-\mathrm{IM}$, non-herbivorous diet with a less-muscular gizzard; $\mathrm{nH}-\mathrm{M}$, non-herbivorous diet with a muscular gizzard.
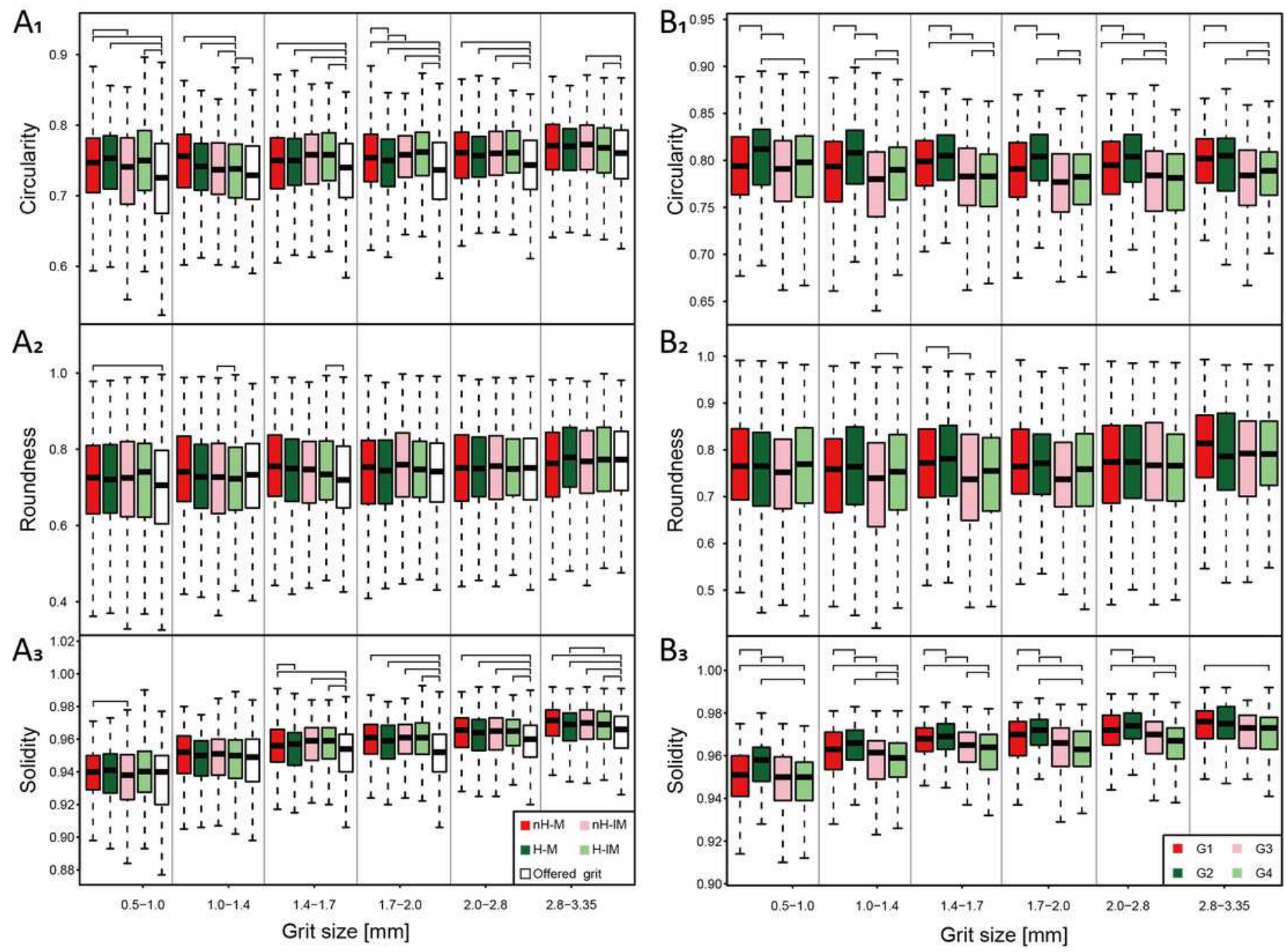
Figure 5

Schematic summary of the results of this experiment

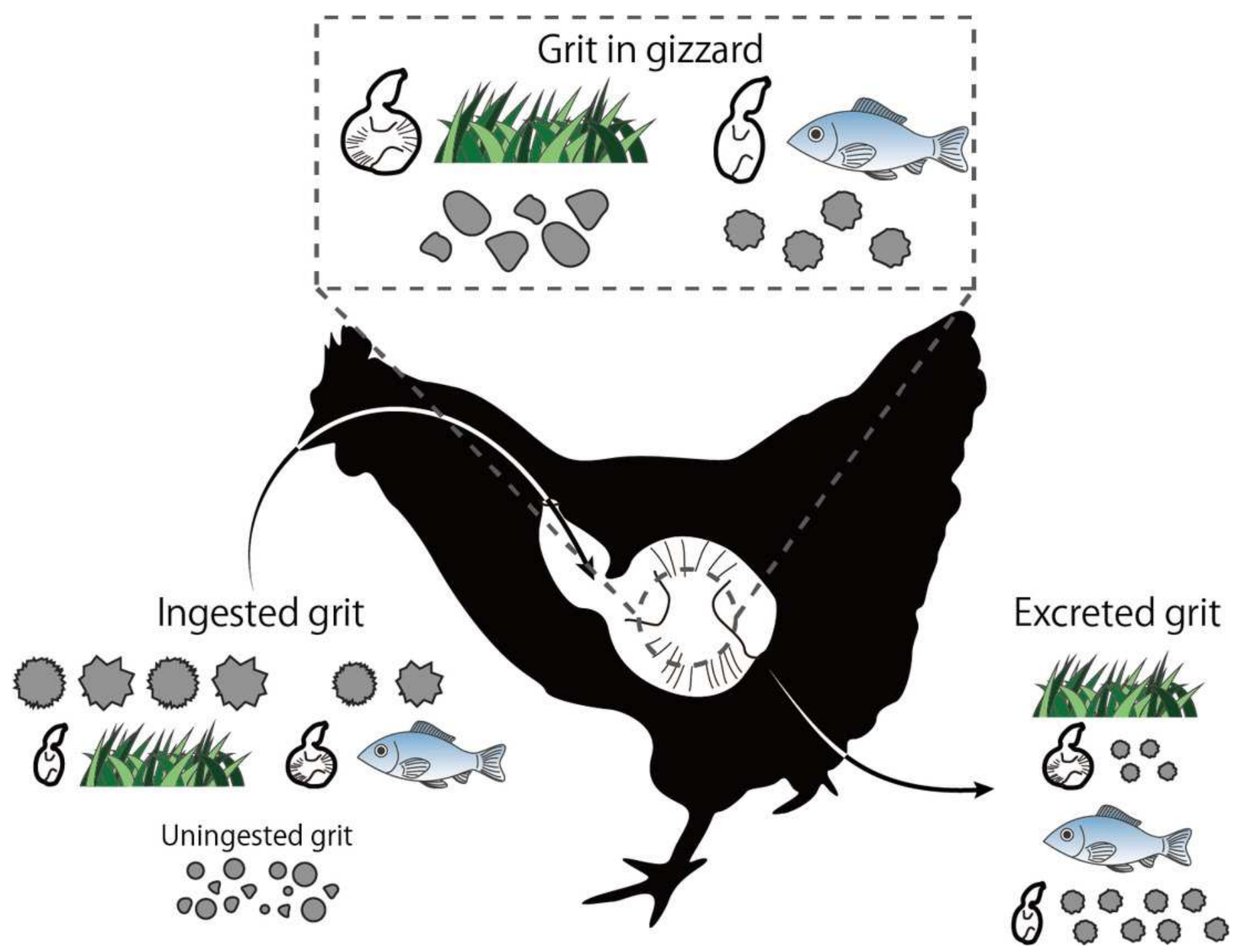




\section{Table $\mathbf{1}$ (on next page)}

Average values of chick status, grit amount, and grit size.

Note that average sizes of offered and remained grit cannot be calculated, but assumed from the amount of stones ingested per size class. See Fig. 3 and Table S3 for detail.

Abbreviations: $\mathrm{H}-\mathrm{IM}$, herbivorous diet with a less-muscular gizzard; $\mathrm{H}-\mathrm{M}$, herbivorous diet with a muscular gizzard; $\mathrm{nH}-\mathrm{IM}$, non-herbivorous diet with a less-muscular gizzard; $\mathrm{nH}-\mathrm{M}$, nonherbivorous diet with a muscular gizzard. 


\begin{tabular}{|c|c|c|c|c|c|c|c|c|c|c|c|c|c|c|}
\hline \multirow{2}{*}{$\begin{array}{l}\square \\
\square\end{array}$} & \multicolumn{4}{|c|}{ Chick [g] } & \multicolumn{6}{|c|}{ Grit amount $[\mathrm{g}]$} & \multicolumn{4}{|c|}{ Grit size $[\mathrm{mm}]^{* *}$} \\
\hline & Body mass & SD & Gizzard mass & SD & Ingested & SD & Gizzard & SD & Feces & SD & Uningested & Gizzard & $\mathrm{SD}$ & Feces \\
\hline \multicolumn{15}{|c|}{ Raw values } \\
\hline H-lM & $182.736^{\mathrm{a}}$ & 33.769 & 7.531 & 1.484 & $4.852^{\mathrm{ab}}$ & 3.484 & 1.305 & 0.525 & $0.09 *$ & $\mathrm{NA}$ & NA & $1.884^{\mathrm{ab}}$ & 0.340 & $0.960^{\mathrm{a}}$ \\
\hline H-M & $153.403^{\mathrm{bc}}$ & 26.688 & 7.863 & 1.483 & 3.657 & 2.572 & 1.118 & 0.498 & $0.26^{*}$ & NA & NA & $1.743^{\mathrm{acd}}$ & 0.355 & $0.975^{b c}$ \\
\hline $\mathrm{nH}-\mathrm{lM}$ & $225.163^{b}$ & 56.007 & $6.636^{\mathrm{a}}$ & 1.501 & $1.879^{\mathrm{a}}$ & 1.252 & 0.781 & 0.634 & $1.34^{*}$ & NA & NA & $2.003^{\mathrm{ce}}$ & 0.413 & $1.273^{\mathrm{abd}}$ \\
\hline nH-M & $250.977^{\mathrm{ac}}$ & 44.363 & $8.205^{\mathrm{a}}$ & 1.227 & $2.318^{\mathrm{b}}$ & 1.810 & 0.919 & 0.784 & $0.83^{*}$ & NA & NA & $1.883^{\text {bde }}$ & 0.512 & $1.138^{\mathrm{cd}}$ \\
\hline \multicolumn{15}{|c|}{ Relative to body mass } \\
\hline $\mathrm{H}-1 \mathrm{M}$ & NA & NA & $0.041^{\mathrm{abc}}$ & 0.041 & $0.026^{\mathrm{ab}}$ & 0.004 & $0.007^{\mathrm{ab}}$ & 0.003 & NA & NA & NA & $0.332^{\mathrm{ab}}$ & 0.055 & $0.169^{\mathrm{a}}$ \\
\hline H-M & NA & NA & $0.051^{\text {ade }}$ & 0.051 & $0.022^{\mathrm{cd}}$ & 0.006 & $0.007^{\mathrm{cd}}$ & 0.003 & NA & NA & NA & $0.326^{\mathrm{c}}$ & 0.065 & $0.182^{b}$ \\
\hline $\mathrm{nH}-\mathrm{lM}$ & NA & NA & $0.030^{\text {bd }}$ & 0.03 & $0.009^{\mathrm{ac}}$ & 0.005 & $0.003^{\mathrm{ac}}$ & 0.003 & NA & NA & NA & $0.329^{\mathrm{ad}}$ & 0.067 & $0.209^{a b c}$ \\
\hline nH-M & NA & NA & $0.033^{\text {ce }}$ & 0.033 & $0.009^{\text {bd }}$ & 0.004 & $0.003^{\text {bd }}$ & 0.003 & NA & NA & NA & $0.298^{\text {bcd }}$ & 0.087 & $0.180^{c}$ \\
\hline
\end{tabular}

$1{ }^{*}$ Total amount excreted on the last day of the experiment, evaluated on group basis.

$2{ }^{* *}$ Grit size are averaged and compared by grit basis instead of individual basis, unlike chick status and grit amount.

3 a-e Means within a colum sharing a common superscript differ significantly at $\mathrm{p}<0.05$. 


\section{Table 2 (on next page)}

Average values of shape indexes.

Abbreviations: $\mathrm{H}-\mathrm{IM}$, herbivorous diet with a less-muscular gizzard; $\mathrm{H}-\mathrm{M}$, herbivorous diet with a muscular gizzard; $\mathrm{nH}-\mathrm{IM}$, non-herbivorous diet with a less-muscular gizzard; $\mathrm{nH}-\mathrm{M}$, nonherbivorous diet with a muscular gizzard. 


\begin{tabular}{|c|c|c|c|c|c|c|c|c|}
\hline & \multicolumn{8}{|c|}{ Circularity } \\
\hline & Offered & SD & Uningested & SD & Gizzard & SD & Feces & SD \\
\hline H-lM & 0.734 & 0.060 & 0.749 & 0.057 & 0.789 & 0.045 & 0.773 & 0.045 \\
\hline H-M & 0.734 & 0.060 & 0.746 & 0.055 & 0.798 & 0.045 & 0.783 & 0.045 \\
\hline nH-lM & 0.734 & 0.060 & 0.747 & 0.058 & 0.776 & 0.049 & 0.774 & 0.049 \\
\hline \multirow[t]{3}{*}{ nH-M } & 0.734 & 0.060 & 0.752 & 0.054 & 0.780 & 0.051 & 0.777 & 0.051 \\
\hline & \multicolumn{8}{|c|}{ Roundness } \\
\hline & Offered & SD & Uningested & SD & Gizzard & SD & Feces & $\mathrm{SD}$ \\
\hline H-lM & 0.732 & 0.121 & 0.742 & 0.121 & 0.762 & 0.108 & 0.760 & 0.119 \\
\hline H-M & 0.732 & 0.121 & 0.740 & 0.119 & 0.764 & 0.107 & 0.763 & 0.099 \\
\hline nH-lM & 0.732 & 0.121 & 0.738 & 0.122 & 0.745 & 0.113 & 0.762 & 0.116 \\
\hline \multirow[t]{3}{*}{ nH-M } & 0.732 & 0.121 & 0.741 & 0.116 & 0.752 & 0.110 & 0.753 & 0.113 \\
\hline & \multicolumn{8}{|c|}{ Solidity } \\
\hline & Offered & SD & Uningested & SD & Gizzard & SD & Feces & SD \\
\hline H-lM & 0.950 & 0.021 & 0.954 & 0.021 & 0.961 & 0.016 & 0.947 & 0.020 \\
\hline H-M & 0.950 & 0.021 & 0.953 & 0.020 & 0.964 & 0.015 & 0.953 & 0.016 \\
\hline nH-lM & 0.950 & 0.021 & 0.954 & 0.021 & 0.959 & 0.016 & 0.953 & 0.016 \\
\hline nH-M & 0.950 & 0.021 & 0.955 & 0.019 & 0.954 & 0.017 & 0.951 & 0.017 \\
\hline
\end{tabular}

1 